\title{
Prospects for Neural Stem Cell-Based Therapies for Neurological Diseases
}

\author{
Jaime Imitola \\ Center for Neurologic Diseases, Department of Neurology, Brigham and Women's Hospital, Harvard Medical School, \\ Boston, Massachusetts 02115
}

Summary: Neural stem and progenitor cells have great potential for the treatment of neurological disorders. However, many obstacles remain to translate this field to the patient's bedside, including rationales for using neural stem cells in individual neurological disorders; the challenges of neural stem cell biology; and the caveats of current strategies of isolation and culturing neural precursors. Addressing these challenges is critical for the translation of neural stem cell biology to the clinic. Recent work using neural stem cells has yielded novel biologic concepts such as the importance of the reciprocal interaction between neural stem cells and the neurodegenerative environment. The prospect of using transplants of neural stem cells and progenitors to treat neurological diseases requires a better understanding of the molecular mechanisms of both neural stem cell behavior in experimental models and the intrinsic repair capacity of the injured brain. Key Words: Neural stem cells, neural progenitors, neurospheres, self-renewal, multipotency.

\section{INTRODUCTION}

Multipotent and self-renewing precursors termed neural stem cells (NSCs) reside in specialized molecular microenvironments in the adult mammalian brain. The fundamental properties of stem/progenitor cells are selfrenewal, multipotency, and migration. ${ }^{1,2}$ Due to these intrinsic properties, neural stem and progenitor cells offer the clearest potential for cellular therapy in the brain. Neural stem cell-based therapy encompasses all the strategies to use the biology of NSCs to ameliorate human neurological diseases and should not be limited to transplantation. For example, alteration in neural progenitor cell properties of migration and proliferation is the basis of some CNS human disorders. ${ }^{3,4}$

The interest in NSCs has been driven primarily by the prospect of using them to treat acute and chronic neurodegenerative diseases of the CNS. For this goal to be feasible, NSCs must demonstrate the ability to differentiate into multiple lineages, migrate long distances, and survive in the environment of the injured brain. Furthermore, NSCs must not display oncogenic transformation. Additional properties of NSCs have been recently dis-

Address correspondence and reprint requests to: Jaime Imitola, MD, 77 Avenue Louis Pasteur, Boston, MA 02115. E-mail: jimitola@ rics. bwh.harvard.edu. covered, including a beneficial paracrine effect that can be achieved by transplanted NSCs and embryonic stem cells. $^{5-7}$ NSCs have also been shown to have immumodulatory properties. ${ }^{8}$ These additional properties make NSCs an attractive source of material for clinical transplantation; however, these properties may be modified by in vitro culturing, which is therefore a matter of great concern in the field. ${ }^{9,10}$

One of the crucial questions in regenerative medicine is whether exogenous or endogenous NSCs are an appropriate source of cells for repair. In the CNS, several studies that have examined the responses of endogenous stem cells in the injured brain have found neuron replacement to be small. ${ }^{11}$ Several strategies have been proposed to expand the pool of endogenous progenitors. ${ }^{12-18}$ The success of these techniques remains to be determined. However, even if endogenous stem cells could be recruited to yield relevant neural cells, several challenges remain, such as generating adequate numbers of cells with proper phenotypes and integrative capacity.

The objective of this review is to examine the current evidence and the challenges of NSCs, as well as how new discoveries in NSC biology are helping to delineate their limitations and potential for brain repair. It should be emphasized that the study of the intrinsic properties of NSCs and biological basis of host-NSCs interactions are 


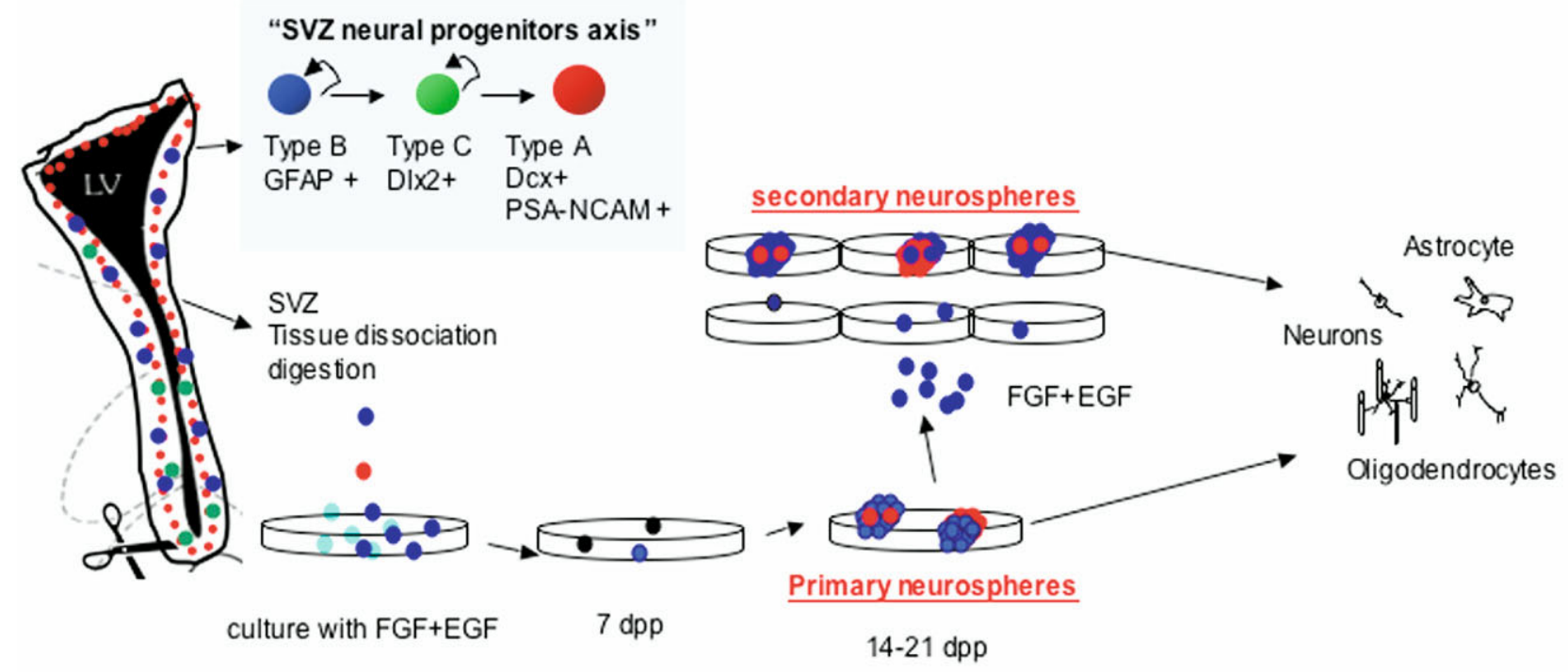

\author{
Self-renewal associated genes \\ EGF, FGF-2, LIF,SOX2,BMI-1, \\ p21,LGL1,SHH,p16INK4,Pigment \\ Epithelium derived Factor (PEDF),PTEN \\ p53, Jagged1,NPC1,Musashi1,PDGF.
}

\author{
Migration associated genes \\ CXCR4, CD44, CCR2,CXCR2, \\ SLIT2, Integrins, \\ Reelin, DCX,PSA-NCAM, \\ MMP2, EMX2.
}

\author{
Differentiation associated genes \\ Hes 1, Hes5, neurogenin1, \\ Neurogenin 2,SOX10, Olig1,2, GLI1, \\ Wnt3,Wnt5, NOTCH,NUMB,GDNF, \\ EPO,TH, LIF.
}

FIG. 1. Diagram shows self-renewal and multipotency of neural stem cells (NSCs). The NSCs can be isolated from the subventricular zone (SVZ), a strip of tissue around the ventricles in the adult CNS. These areas exhibit the following cellular organization: type B cells (blue) are considered the bona-fide NSCs, express glial fibrillary acidic protein (GFAP), and are believed to be a remnant of the radial glial progenitors during neural development. The type $\mathrm{C}$ cell is a transit-amplifying progenitor (green) that is a highly proliferative cell and generates type A cells that are neuronal progenitors, which migrate to the olfactory bulb in the mice brain and express double cortin. The NSCs can be isolated by dissociating the SVZ and plating the cells in FGF-2 and EGF containing medium. After several days, bona fide NSCs and type C cells generate neurospheres that contain not only stem cells but also more differentiated progenitors. NSCs can differentiate into astrocytes, neurons and oligodendrocytes. Furthermore, NSCs can be dissociated again and replated at single cell/well density in fibroblast growth factor (FGF)-2 and epidermal growth factor (EGF) to generate another wave of self-renewal progenitor cells. If the resulting cells can differentiate into the three lineages of the CNS (i.e., oligodendrocytes, neurons and astrocytes), then these cultures fulfill the criteria of containing NSCs, and the self-renewing capacity can be preserved through multiple passages. However, suboptimal culture methodology can induce aneuploidy and transformation. The bottom panel presents a nonexhaustive list of molecules that are associated with the different intrinsic properties of NSCs.

of critical importance when assessing the clinical applications of NSCs, which provide a framework for realistic applications of NSCs to human neurological disorders.

\section{Properties of NSCs for therapeutical use}

Self-renewal of NSCs. The major interest of NSCs as therapeutic vehicles stems from their intrinsic properties. ${ }^{19}$ The term self-renewal is used to define the capacity of a clone to generate new stem cells with identical properties from generation to generation, a characteristic that can be promoted by cytokines such as epidermal growth factor (EGF), b-fibroblast growth factor (bFGF), and leukemia inhibitor factor among others (FIG. 1). ${ }^{19}$ Progenitor cells are a step further along than NSCs in the differentiation process; they have committed to a particular lineage. Some neural progenitor cells, such as oligodendrocyte progenitor cells (OPCs), may exhibit multipotency in vitro in certain circumstances. ${ }^{20-22}$ Some investigators have found stem-like cells within a "glial" population isolated from the postnatal and adult cortex, as well as the adult optic nerve; such immature "glia" give rise to neurons as well as mature oligodendrocytes and astrocytes. ${ }^{23-25}$ However, controversy exists about the multipotency of other cells such as ependymal cells. ${ }^{14}$

NSCs will self-renew in response to EGF and/or bFGF. This proliferative response can be used to isolate and expand stem-like cells from the CNS where they form clusters of cells termed neurospheres from primary dissociated neural cultures. It should be emphasized that a single cluster does not equal a clone unless it has been proven to derive from a single isolated cell in a single well. ${ }^{14,26-32}$ Self-renewal implies that a single NSC can give rise to differentiated cells as well as to other NSCs that can be similarly placed into an isolated well and give rise to both differentiated and undifferentiated progeny. The previously mentioned assessment constitutes an op- 
erational definition of a stem cell and remains today the only valid way of discerning a self-renewing and multipotent NSC (FIG. 1).

NSCs reside in specific germinative zones in the embryonic and adult mammalian CNS. ${ }^{2}$ These zones include the subventricular zone (SVZ), the external germinal layer of the cerebellum, and the subgranular zone of the dentate gyrus, ${ }^{1}$ from where they can be isolated. ${ }^{33}$ Recent elegant studies have demonstrated the constituents of human SVZ and the potential of NSC isolated from this neurogenic niche. ${ }^{34,35}$ The adult $\mathrm{SVZ}^{36}$ is composed of different types of cells (FIG. 1): 1) type A cells migrate neuronal precursors that migrate to the olfactory bulb and express double cortin; 2) type B cells are nestinpositive, glial fibrillary acid protein (GFAP)-positive astrocytes that exhibit NSC properties; and 3) type C cells are nestin-positive transient $d l x-2$ positive amplifying progenitors cells. ${ }^{37}$ Current evidence suggests that in the adult SVZ, bona fide neural stem cells express GFAP. ${ }^{38}$ During development or when injury occurs, NSCs proliferate either by symmetric division, where each cell divides into two new NSCs, or by asymmetric division, where the NSC gives rise to one new NSC and one progenitor cell such as a double cortin plus A cell that can migrate out of the SVZ to areas of injury. ${ }^{39}$

Multipotency of NSCs. Multipotency is the ability of a single NSC clone to give rise to the three major types of cells in the CNS: 1) neurons, 2) oligodendrocytes, and 3) astrocytes. Recently, claims of pluripotency have been made. The term pluripotency refers to the capacity of stem cells to give rise to the full range of cells and tissues in an organism, a unique property of embryonic stem (ES) cells. Several controversial observations during the past several decades have suggested that other stem cells, including NSCs, may have such potential under extraordinary nonphysiological circumstances. ${ }^{40,41}$ However, other groups failed to reproduce such findings. ${ }^{9}$ Alternative explanations such as fusion, rather than authentic transdifferentiation, may explain some of the claims of pluripotency of neural stem cells. ${ }^{42-44}$ These findings may have implications when one is considering sources of stem cells for repair in neurodegenerative disorders. The rationale of choosing hematopoietic stem cells and mesenchymal stem cells as sources of neurons for neurodegenerative disorders is less robust. Mesenchymal stem cells have shown clinical efficacy, but not convincing neuronal differentiation, and their therapeutic effects in these models appear to be a result of their paracrine effects. $^{45}$

Besides the self-renewing capacity and multipotency of NCSs, perhaps the most critical biological property of NSCs is their extraordinary migration toward sites of injury. ${ }^{27,46-49}$ The mechanism of this migratory capacity is beginning to be elucidated ${ }^{50}$ and makes them potent vehicles for molecular therapy. Another promising prop- erty for clinical application is the ability of NSCs to produce bioactive molecules and growth factors, which may help to modulate the environment and promote beneficial effects in the host. ${ }^{51,52}$

\section{Ability of transplanted human and mouse NSCs to ameliorate neurological disorders in experimental models}

Human neural stem cells (hNSCs) have been isolated, making it possible for the preclinical testing of clones of hNSCs. Several laboratories have isolated multipotent neural stem cells from fetal or adult sources. $^{12,35,53-55}$ hNSCs transplanted into neonatal immunodeficient mice proliferated, migrated, and differentiated in a site-specific manner. ${ }^{18}$ In vitro priming procedures have been used to generate a nearly-pure population of neurons from fetal hNSCs for transplant into adult rat $\mathrm{CNS}^{56}$ Others have shown that human neural stem cells, transplanted into neurogenic regions in the adult rat brain (the subventricular zone and hippocampus), migrated specifically along the routes normally taken by the endogenous neuronal precursors and exhibited site-specific neuronal differentiation in the granular and peri-glomerular layers of the olfactory bulb and in the dentate granular cell layer of the hippocampus. The cells also migrated to the striatum and differentiated into both neuronal and glial phenotypes. ${ }^{57,58}$

Many diseases have been suggested as a target for stem cell therapy, ${ }^{59}$ and neurodegenerative disorders top the list. Despite the enthusiasm for their use, detailed analyses of the biology and limitations of NSCs and the pathology of target disease are both necessary to increase the likelihood of clinical success. ${ }^{60}$ For example, in ischemic stroke, the goal of therapy is to restore blood flow within minutes of the event, avoiding secondary cell death. This objective of secondary prevention is obtained with rapid intervention by vascular neuroradiology and medication. Therefore, the potential role of neural stem cells in this acute phase is limited. After this stage it is relevant to consider the potential role of stem cells to increase repair and facilitate recovery. In animal models of stroke and spinal injury, neural stem cell transplantation has shown efficacy. NSCs implanted into ischemic brain engrafted, survived, and differentiated into neurons as well as glia, in contrast to limited differentiation of NSCs in the normal adult to a glial phenotype. ${ }^{61}$ In ischemic injury, NSCs transplanted into the ventricles migrated to and throughout the infarct cavity and engrafted and differentiated into all major neural cell types. $^{62,63}$ In addition, tissue-engineering constructs of NSCs have shown robust integration and reparative phenotype in a model of hypoxic-ischemic injury, with reduction of parenchyma loss, increase in directed neurite outgrowth, and reduction in glial scarring. ${ }^{64}$ This work 
suggests injured brain can be permissive for the NSC transplants and endogenous stem cells. ${ }^{65}$ Integration and reconstruction of circuitry is an important goal for NSC transplants during injury. In this regard, several groups have shown that that in vitro expanded CNS precursors, after transplantation into the brains of rats, form electrically active and functionally connected neurons ${ }^{66}$ and integrate into host cortical circuitry. ${ }^{61,64,67}$

In spinal cord injury, transplanted neural progenitor cells integrated along axons surrounding the lesion site. These cells differentiated only along astro- and oligodendroglial lineages, supporting the notion that the adult injured spinal cord provides molecular cues for glial differentiation, but not for neuronal differentiation. ${ }^{68}$ However, it has been shown that neural progenitor cells from the spinal cord may harbor neuronal capabilities, but activation of the Notch pathway during injury may limit their neuronal regenerative potential. ${ }^{69}$ To address this limitation, NSCs have been transplanted into the spinal cord engineered to express neurotrophin-3. The cells migrated long distances and differentiated into neurons and glia. ${ }^{52}$

NSCs may provide substrates for cell replacement, but there is also evidence for protective bystander effects that improve the survival of host cells after experimental contusion in rats and other models of injury. ${ }^{70,71}$ These effects are due to the secretion of bioactive molecules by transplanted neural stem cells. NSCs constitutively secrete substantial quantities of neurotrophic factors that can support extensive growth of host axons, as well as host cell survival.

Models of neurodegeneration. Many neurodegenerative disorders represent important targets for stem cell therapy. However, a realistic consideration of the complexity of these disorders is required. For instance, in Alzheimer's disease (AD) the neurodegeneration is multifocal and its amelioration would require the use of multiple transplants in each patient. This approach would be problematic and mandates that we attempt to achieve reasonable engraftment by systemic or intravenous administration. It could be argued that a paracrine or bystander effect might be beneficial in $\mathrm{AD}$ to preserve remaining neurons, even if cell replacement was not achieved. However, more research is required to demonstrate whether the paracrine effect observed in some studies of neural stem cells and embryonic stem cells could be of any benefit in AD models. The therapeutic role of neural stem cells in such devastating and multifocal disorders as AD may have a coadjutant rather than a primary role. In addition, the evidence of any benefits of neural stem cells in preclinical testing is lacking. The current approach to experimental therapies of $\mathrm{AD}$ is focused on the underlying neurobiology of the disease, including buildup of $\mathrm{A} \beta$ and the neuronal dysfunction that occurs. Furthermore, $\mathrm{A} \beta$ transgenic animals have an impairment of neurogenesis due to deleterious effects of $\mathrm{A} \beta$ to neural progenitors. ${ }^{72}$ These considerations suggest that any neural stem cell therapy for AD should be accompanied by efforts to decrease the altered microenvironment that may jeopardize neural stem cell survival. In spite of widespread claims of stem cell therapies for $\mathrm{AD}$, a great deal of preclinical research will be required to establish the potential for neural stem cell therapy for AD.

More circumscribed neurological disease may be amenable to NSC therapy, especially when a single biochemical defect is apparent. ${ }^{59}$ In Parkinson's disease (PD), fetal tissue grafts have been used in rodent and primate models, ${ }^{73}$ as well as in clinical trials. ${ }^{74,75}$ However, short graft survival and limited integration of the grafts appeared to reduce the usefulness of this approach. Cells derived from the fetal midbrain can modify the course of the disease, but they are an inadequate source of dopamine-synthesizing neurons. Immortalized rodent neural progenitor cells were transplanted into primate and rodent PD models leading to increased tyrosine hydroxylase in the brains of transplanted animals. ${ }^{76}$ Others transplanted neuronal progenitor cells derived from neonatal rat SVZ into the striatum of adult rats after unilateral 6-hydroxydopamine lesions. The NSCs survived and migrated, and many differentiated into neurons. ${ }^{77}$ These results indicate that the lesioned brain contains intrinsic cues sufficient to direct the specific expression of dopaminergic traits in immature multi-potential neural stem cells. In this context, stem cells appear to be superior to fetal tissue grafts and represent new hope for the treatment of PD. Others have shown that human neural progenitor cells can differentiate into a small number of neurons that expressed tyrosine hydroxylase and were sufficient to partially ameliorate lesion-induced behavioral deficits in some animals. ${ }^{78}$ More research in primates is required to address the potential of NSCs in PD models. In this regard, NSCs appear to prevent alteration in dopaminergic neurons induced by 1-methyl-4-phenyl1,2,3,6-tetrahydropyridine (MPTP) ${ }^{79}$ Human NSCs transplanted into brains of primates after MPTP administration appear to improve disease severity, operating through multiple mechanisms. ${ }^{80}$

One source of stem cells that has shown great promise is the ES cells. In vitro, an enriched population of midbrain neural stem cells can be derived from mouse or human ES cells. The dopamine neurons generated by these stem cells show electrophysiological and behavioral properties expected of neurons from the midbrain $^{81,82}$; however, they do have the potential to persist as an undifferentiated conglomerate of cells in vivo with the risk of tumorigenic transformation. ${ }^{83}$

Demyelinating disorders. In multiple sclerosis (MS), oligodendrocytes and axons are destroyed and neurons are dysfunctional. ${ }^{84,85}$ To address this patholog- 
ical process, transplanted NSCs would need to differentiate into both oligodendrocytes and neurons. The feasibility of using NSCs has been demonstrated in several animal models of demyelinating disease. Importantly, NSCs injected intravascularly in experimental autoimmune encephalomyelitis (EAE), a model of MS, successfully ameliorated disease, ${ }^{51}$ circumventing the need for multifocal injections in the CNS. In addition, the use of immature multi-potent progenitors may be more beneficial, given that NSCs can not only replace neurons and oligodendrocytes but can serve as modulators of the microenvironment. ${ }^{51}$ It remains unclear whether the benefits of NSCs in EAE are derived from their ability to immunomodulate encephalitogenic $\mathrm{T}$ cells in the periphery or in the CNS, to modify the destructive inflammatory environment in the CNS, or to replace damaged neural cells. ${ }^{86}$

Several groups have shown that NSCs can differentiate into mature oligodendrocytes in models of dysmyelination, including $($ shi $)$ mice $^{87}$ myelin deficient $(m d)$ rats; ${ }^{88}$ and the shaking (Sh) pup canine myelin mutant. $^{88,89}$ NSCs undergo abundant oligodendrocyte differentiation and mediate clinical improvement. ES cells have also been shown to differentiate into oligodendrocytes and myelinate in vivo in shi mice ${ }^{90}$ and $m d$ rat. $^{91}$ Transplanted OPCs repair focal demyelinated areas in the neonatal and adult canine mutant, ${ }^{92}$ and in the $m d$ mutant rat. ${ }^{93}$ These cells can be isolated from the rat SVZ as well and produce robust myelin after transplantation. ${ }^{94}$ Other cells such as olfactory ensheathing cells and Schwann cells have also shown efficacy. Purified populations of human olfactory ensheathing cells remyelinate persistently demyelinated CNS axons and induce axonal regeneration $^{95}$ after transplantation into experimentally induced demyelinating lesions in the rat spinal cord. ${ }^{96,97}$ Human OPCs myelinate shiverer mouse brain; adult OPCs myelinated more rapidly than their fetal counterparts, generated oligodendrocytes more efficiently than fetal OPCs, and ensheathed more host axons per donor cell than fetal cells. ${ }^{55}$ In addition, Schwann cells have been used for transplantation into demyelinated areas; human Schwann cells were transplanted into the X-irradiation/ethidium bromide-lesioned dorsal columns of rats showing extensive remyelination, engraftment, and improved conduction velocity by electrophysiological analysis several weeks after transplant. ${ }^{98}$ These results indicated that several types of progenitors and Schwann cells may be used for remyelinating therapy and that transplanted cells receive environmental cues that drive their migration and differentiation toward oligodendrocytes.99

Cerebellar degeneration and metabolic diseases.

In an animal model of cerebellar degeneration, the newborn meander tail mice (mea), which are characterized by the lack of development of cerebellar granule cells, transplanted NSCs differentiate into neurons. ${ }^{100}$ More recent work in the Purkinje cell neurodegeneration mutant nervous $(n r)$ mice has demonstrated that NSCs exert a powerful chaperone effect, physically interacting with Purkinje neurons, reestablishing altered homeostasis, and protecting these cells from neurodegeneration. ${ }^{5}$ In addition, NSCs have shown great success in models of neurological metabolic diseases, such as mucopolysaccharidosis VII. ${ }^{101,102}$ Human and mouse NSCs have been engineered to express the human form of the enzymes defective in Tay-Sachs disease ${ }^{103,104}$ and in Krabbe disease. It was recently demonstrated that NSCs isolated from mouse or human sources, as well as human embryonic stem (hES)-derived neural progenitor cells, appeared to delay disease onset and prolonged survival in a mouse model of Sandhoff disease, suggesting that all these cell types produce bioactive molecules that modify neurodegenerative disease. ${ }^{105}$ These diseases are typically lethal or result in severe mental retardation and neurodegeneration. The early use of NSCs to restore missing enzymes may have a tremendous impact on the survival and function of affected individuals.

Brain cancer. NSCs briskly home to brain tumors, ${ }^{27}$ and several groups have exploited this extraordinary homing capacity to attempt to modulate glioma growth. These studies involved injecting genetically modified NSCs using a variety of gene products, such as tumor necrosis factor-related apoptosis-including ligand (a proapoptotic molecule), and the results demonstrated glioma apoptosis and growth reduction. Others used inflammatory cytokines such as interleukin-12 or interleukin-4 that can enhance T-cell infiltration and durable antitumor immunity. ${ }^{106-108}$ Although beyond the scope of this review, an important consideration is the potential origin of brain tumor from NSCs. It has been shown that neural progenitors have the potential to undergo malignant transformation into gliomas upon oncogene expression. Furthermore, infusion of growth factors can modify the SVZ and generate low-grade glioma-like growths. ${ }^{109}$ This potential for neoplastic transformation is a crucial aspect for the therapeutic application of neural stem cells, ${ }^{110}$ although spontaneous transformation of transplanted NSCs (including immortalized NSCs) into gliomas has not been observed. On the other hand, the potential for transformation of ES cells transplanted to the CNS remains worrisome, as shown in a recent experimental trial in a PD model. ${ }^{83}$

\section{Current challenges of neural stem cell-based therapy}

It remains to be determined whether any particular human CNS disease will benefit from NSCs transplantation. ${ }^{59}$ Careful planning and extensive animal testing will be required before clinical studies can be entertained. Theoretically, diseases in which clinical effi- 


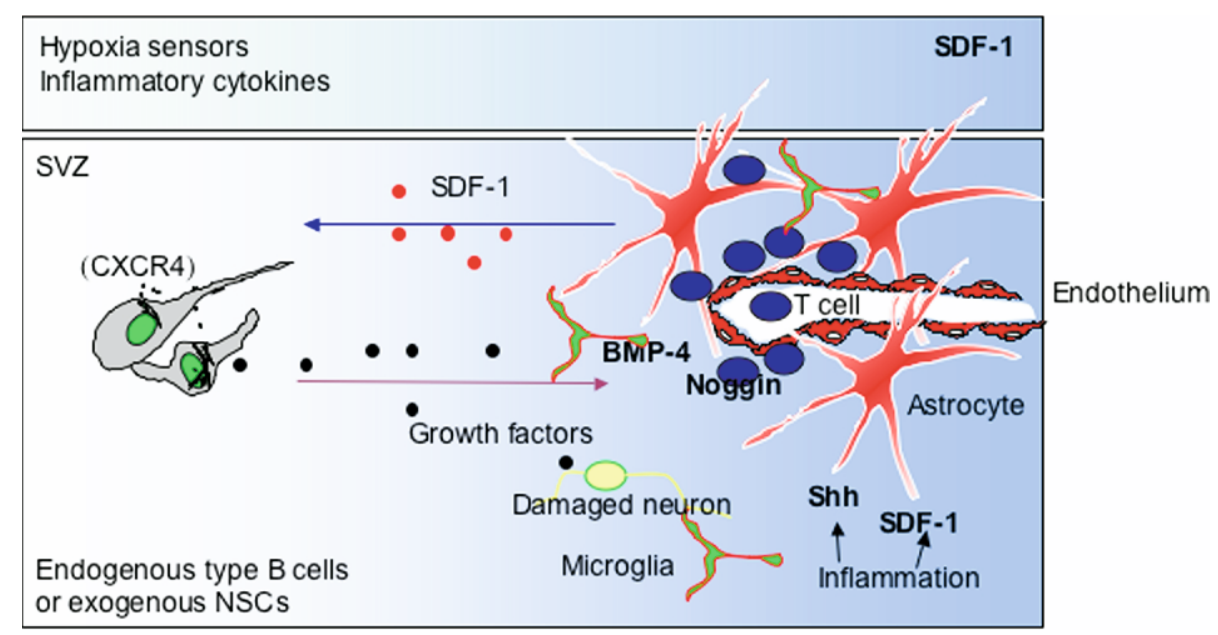

FIG. 2. Diagram of reciprocal interaction of neural stem cells (NSCs) with an inflamed microenvironment. The concept of injury-induced niche. NSCs from the subventricular zone (SVZ) or exogenous stem cells can sense areas of injury in the CNS by virtue of the expression of chemokine receptors such as CXCR4. The injured brain, especially the gliovascular interface can establish an atypical injury-induced niche, and different types of cells may participate in these areas (i.e., perivascular astrocytes [red] and endothelial cells lining the vessel as well as immune cells, such as T cells [blue] or microglia [green]). All these cells by virtue of the secretion of stem niche regulators may create a permissive microenvironment during the acute phase of injury. Several stem cell regulators have been found in these areas (i.e., CXCL12, Noggin, and BMP-4). Furthermore, the reciprocal interaction is achieved when NSCs express growth factors that can modulate the inflammatory response and improve the survival of altered neural cells establishing a bidirectional interaction that is the basis of the chaperone effects of NSCs. In addition, these cells can differentiate into neurons and replace missing cells. (Modified from Ref. 50).

cacy could be determined by a single biological mechanism, such as Parkinson's or Huntington's disease, might have increased chances of success. MS and AD represent higher-order challenges because their pathology is widespread, affecting multiple sites in the CNS and impairing neuronal, as well as glial, functions. While targeting localized lesions that cause great disability can be contemplated, addressing multiple lesions that extend throughout the CNS remains a great challenge, even with migratory NSCs. Reparative therapy with NSCs must be applied in concert with other equally important traditional therapies that aim to ameliorate degeneration and promote neuroprotection as informed by the molecular pathology of the particular neurological disorder. In addition, we need to learn the extent to which an inflammatory and neurodegenerative microenvironment might promote or hinder neural stem cell function (FIG. 2). ${ }^{60,72,111-113}$

Source of human neural stem cells: neurospheres, immortalized, or ES-cell derived? Primary human NSCs may be obtained through the following routes: primary neurosphere cultures or primary immortalized or ES-cell derived NSCs. Therefore, questions arise regarding the best sources of stem cells and the most efficacious methods to generate them. Pluripotent hES cells (an area of great ethical debate) are self-renewing and pluripotent. $\mathrm{hES}$ cells may provide an unlimited supply of rapidly dividing cells that can differentiate along any lineage. However, with hES cells we must be certain to direct them down a given lineage and to avoid the emergence of inappropriate non-neural cells or teratocarcinomas. Alternative sources of NSCs and protocols for differen- tiation are being explored. A discouraging outcome of this line of research is the limited differentiation of NSCs into dopaminergic neurons, a pathway that is preserved in embryonic stem cells. Nevertheless, recent findings suggest that human astrocytes residing in the periventricular areas behave as NSCs and exhibit multi-potency. These cells can be isolated from individuals by brain biopsies. ${ }^{35}$ Other adult human neural progenitors can be safely isolated from cadavers, ${ }^{53}$ although their ability to generate dopaminergic neurons is unknown.

Numerous challenges confront those who would isolate human neural progenitors. Human somatic stem cells are often slow to expand and may senesce, unless genetically augmented. Autografts of immunologically compatible and less ethically problematic adult stem cells are often proclaimed as being promising for neurodegenerative diseases. Grafting a patient's own cells may appear to circumvent ethical and immunologic concerns; however, the practical challenges could be overwhelming because each new patient will require the prospective isolation, expansion, and characterization of their NSCs. This process will be costly in time, resources, and personnel, and will be dogged by potential variability between preparations. In addition, if the etiology for disease progression resides in the host genome or is a genetic defect (i.e., as in HD, familial amyotrophic lateral sclerosis, or $\mathrm{AD}$ ), then autologous endogenous progenitors will also be genetically flawed and will not represent a good source for repair. ${ }^{19,114-116}$ If the process is noncell-autonomous, then implanting exogenous cells may be problematic, unless they can be resistant to the microenvironment that caused the injury. 
An alternative to autografts is the use of genetically established somatic stem or progenitor cell lines. Using established immortalized NSCs, all paradigms of neural stem cell therapy can be achieved. These cells have been used extensively and have contributed to our understanding of NSC behavior and therapy during neurodegeneration. ${ }^{27,61,70,77,87,101,103,117-121}$ Recently, Roy et al. ${ }^{16}$ showed that retroviral overexpression of human telomerase reverse transcriptase can immortalize neural progenitors from the human fetal spinal cord. ${ }^{122}$ The cells could be passaged without evidence of senescence, karyotypic abnormality, or loss of normal growth control. After transplantation into developing rat fetal telencephalon or spinal cord, no neoplasms formed in the small number of animals studied and neuronal markers persisted in vivo with an absence of glial markers. ${ }^{16,122}$ The feasibility of obtaining immortalized hNSCs has been recently demonstrated using $v-m y c$; these hNSCs downregulate the immortalizing gene and show neuronal differentiation. These data suggest that gene-based methods for generation of NSC clones are not inherently dangerous. Of course, more extensive research is required to verify that they are not prone to form tumors or aberrant connections and that they will differentiate appropriately in a great numbers of neurodegenerative disorders, a standard that has been substantially achieved with mouse NSCs. ${ }^{27,61,70,77,87,101,103,117-121,123}$

In vitro generation of neural stem cells by neurospheres. In contrast to hematopoietic stem cells in which a small number of stem cells can regenerate multiple cells types, NSCs do not regenerate progeny with the same efficiency, and it is not possible to use a small number of cells to regenerate the entire repertoire of neurons, oligodendrocytes, and astrocytes. Therefore, NSCs need to be propagated in vitro by using FGF-2 or EGF. One strategy is to use neurosphere cultures; neurospheres represent a nonclonal population of neural progenitors cells that include progenitors in different stages and exhibit physiological capacity to respond to FGF 2 -and EGF. ${ }^{4}$ The efficiency of generating neurospheres has been used as a surrogate for neural stem cell activity in vivo, although this approach is controversial. ${ }^{124}$ In addition, the neurosphere assay remains under scrutiny because of the long-held assumption that neurospheres are clonal. Although it is true that stem cells cultured in vitro at a dilution of one cell per well can form neurospheres that are multi-potent and self-renewing, the clonal efficiency of these cultures is very low. Thus, most investigators culture neurospheres under the so-called clonal dilution of 10 to 20 cells per $\mu \mathrm{L}$. These neurospheres are not clonal and a recent report demonstrated significant fusion of neurospheres at this density. ${ }^{125}$ Moreover, in vitro expansion may modify the properties of NSCs, sometimes after only a few passages, which can lower the threshold for transformation and increase the potential to induce brain tumors. ${ }^{126,127}$ In this regard, aneuploidy is a recognized phenomenon of neural stem cells cultures. In addition, aneuploidy can be seen in ES cells dissociated with trypsin. ${ }^{9}$ Neurospheres can be transformed by culture after 10 to 15 passages, ${ }^{9}$ but adult NSCs do not exhibit transformation in vitro. Therefore, more research is needed to clarify the appropriate methods of culturing NSCs to avoid aneuploidy and genomic instability. ${ }^{128}$ Because one or two tumorigenic hits can render neural progenitors cells highly oncogenic leading to gliomas, ${ }^{129}$ NSCs expanded in culture for clinical use in humans will require genetic examination to clarify their tumorigenic potential. These studies will include karyotyping to detect aneuploidy or comparative genomic hybridization to detect microdeletions.

Because of the need to expand neural stem cells in vitro, a debate is currently ongoing among researchers as to whether in vitro manipulations change the properties of stem/progenitor cells. Some cells that are restricted progenitors in vivo, such as $d l x-2$ or type $\mathrm{C}$ cells, can acquire stem cell properties such as multipotency in vitro. ${ }^{37}$ Moreover, in vitro propagation with FGF-2 may change some of the intrinsic properties observed in vivo. ${ }^{130}$ Taking lessons from the ES cell field, we should use the same rigorous methodology for culturing hNSCs. More specific research is required to determine the safety of these cells in humans. Nevertheless, neurospheres isolated from individuals with genetic alterations may be useful for research if used in the first passages, and investigators are using neurospheres obtained from individuals with brain abnormalities as surrogate in vitro models for understanding CNS disease and development. ${ }^{3,4}$

\section{New biological insights in regeneration from neural stem cell-based transplantation: relevance for clinical rationale}

An important area for investigation is the molecular interactions between NSCs and the disease microenvironment. Because the paracrine and immunomodulatory function of certain stem cells can be therapeutically valuable, even if integration of the cells in the CNS does not occur, there is evidence of cross-talk between the resident CNS cells with neural stem/progenitor cells that are activated and initiate the process of repair (FIG. 2). In disease models with a prominent inflammatory component, such as stroke, experimental autoimmune encephalomyelitis, and experimental demyelination, the stem cell niches appear activated and exhibit increased proliferation and migration of neural progenitors. ${ }^{131,132}$ Interestingly, exogenously administered neural progenitors appear to participate and modulate disease by reciprocal interactions with the inflamed brain. Understanding the mechanisms of resident CNS cells with NSC interaction is important for development of new therapies to slow the progression of neurodegenerative diseases. Until re- 
cently it was believed that the mechanisms of action of NSCs during injury were cell autonomous and independent of the damaged environment. However, it has been shown that NSCs depend on an inflammatory and damaged environment to function. ${ }^{51,64}$ Other investigators have demonstrated direct immunomodulatory activity of $\mathrm{NSCs}^{8}$ and mesenchymal stem cells. ${ }^{133}$ In EAE, several groups have now shown that immunomodulation with stem cells is achievable via paracrine mechanisms. ${ }^{8}$

In addition immunogenicity of NSC is pertinent for survival, because allogeneic neural stem cells can not survive in the host without immunosupression. ${ }^{134}$ Both embryonic and adult neural progenitor cells may express major histocompatibility complex class I and co-stimulatory molecules, but they do not express surface class II molecules, and thus they are considered less immunogenic than differentiated cells. However, during inflammation, molecules that render NSCs immunogenic are upregulated. ${ }^{113}$ The concern still remains that even though NSCs are less immunogenic than other cells, their differentiated progeny will express class II, which could jeopardize the long-term therapeutic effects of the cells. ${ }^{113}$ More studies are needed to evaluate the potential of chronic rejection in neural transplantation.

The concept of injury-induced niches. Astrocytes and endothelial cells are considered niche cells that support neural stem cells. Astrocytes in the hippocampus support neurogenesis, ${ }^{135}$ but reactive astrocytes (generated by inflammatory stimuli) contribute to astrogliosis. ${ }^{136}$ Although the specific mediators of this response are unknown, inflammatory cytokines play a role in changing the niche function of astrocytes. Microglia can be neurogenic and enhance the neural differentiation of NSCs. ${ }^{137}$ However, lipopolysaccharide-activated microglia (in some paradigms) inhibit neurogenesis. ${ }^{112}$ It has been shown that the survival of oligodendrocyte progenitor cells in the inflamed CNS is dependent on the activation of microglia, but that excessive microglia activation reduces the efficacy of the transplant. ${ }^{138}$ The nature of the activating signal may influence the outcome, as microglia activated with small dosages of interferon- $\gamma$ or the $\mathrm{T}_{\mathrm{H}} 2$ cytokine interleukin- 4 , but not lipopolysaccharide, appear to increase neurogenesis and oligodendrogenesis. ${ }^{139}$ Therefore, acute inflammation changes the intrinsic NSC properties to enhance repair, but the persistence of this abnormal microenvironment may be deleterious to NSC survival.

It is becoming clear that the repair plasticity of the brain requires not only NSC competence, but also the ability of other cells to participate in the repair process. After injury, non-neural cells located outside the typical niche start to recapitulate a developmental process and generate an ectopic or atypical stem cell niche. ${ }^{8,50,65}$ It has been demonstrated that CXCL12 is one of the mediators of ectopic niches. ${ }^{50,60,65}$ These data have been reproduced and ex- tended and have consolidated the CXCL12/CXCR4 pathway as the first molecular pathway formally demonstrated as a mediator of ectopic neural stem cell niches (FIG. 2). ${ }^{50,65,131,140-142}$ These observations suggest that normal brain cells far from the SVZ can create an environment for repair independent of the known stem cell niches. If the SVZ and dentate gyrus were the only sources of NSCs during repair, NSCs would have to migrate very long distances to reach remote areas of injury in the cortex or spinal cord. Interestingly, surviving astrocytes and endothelial cells in areas of injury appear to create a local niche for repair, whereas progenitor cells with known stem cell capacities, such as oligodendrocyte progenitor cells, are distributed in the entire brain, and especially around blood vessels. These observations suggest the possibility that neural progenitors around vessels and far from the normal niches can exert a facultative NSC role and the gliovascular interface can have a facultative stem cell niche role. ${ }^{65}$ Therefore, injury may not only create neo-niches for SVZ cells but also for exogenous NSCs. More work to prove this hypothesis remains, but this possibility suggests that not only the limited areas around the SVZ and DG niches but rather the entire CNS might have the potential for repair. In support of this concept it was shown that a small percentage of exogenous neural cells in EAE remain undifferentiated for a long period of time around vessels. In addition, the injured site and infiltrating immune cells express molecules known to have a role in normal stem cell niches. ${ }^{8}$ More research and validation of other molecular mediators of ectopic niches is necessary (FIG. 2).

\section{CONCLUSIONS}

NSC biology holds tremendous potential for neurological therapy. This approach is not limited to the use of NSC for transplants, but includes the manipulation of endogenous stem cells and the multiple bioactive molecules that they express during reciprocal interactions with the diseased brain. New knowledge of the molecular biology and genetics of NSCs and their bioactive products, as well as the injured microenvironment, will guide and refine our judgment of when and how to use NSCs. In the meantime, several steps are required to move the field toward the ultimate goal: 1) we must better standardize methods and protocols of isolation and culture of hNSCs, 2) we must better evaluate the clinical efficacy of NSC transplants in more adequate animal models, 3) we must study the molecular mechanisms of the limitations of intrinsic brain repair, and 4) we must learn to promote the long-term survival of these cells by creating a more permissive environment in the diseased brain and define the molecular mechanism of the stem cell niche. All of the aforementioned steps will help us to improve our translation of NSC biology to the clinic. 


\section{GLOSSARY OF TERMS}

BMI-1 = B lymphoma Mo-MLV insertion region 1

Transcription factor that mediates the control of selfrenewal of NSCs.

$\mathrm{CCR} 2=$ chemokine, cc motif, receptor 2

This encodes a receptor for the chemokine; monocyte chemoattractant protein-1 (MCP1) is produced by endothelial cells and smooth muscle cells and regulates the NSC migration.

\section{CD44}

This molecule is an integral cell membrane glycoprotein with a postulated role in matrix adhesion lymphocyte activation and lymph node homing, also expressed by neural precursors cells.

CXCR2 = chemokine, cxc motif, receptor 2

This is a chemokine; the receptor for growth-regulated gene (GRO1, or CXCL1) expressed in oligodendrocyte progenitor cells and it modulates the migratory responses.

CXCR4 = chemokine, cxc motif, receptor 4

This is a seven-tramsmembrane protein involved in migration of many cells including hematopoietic stem cells and lymphocytes, it is expressed in NSCs, and it mediated the migration during development and injury.

DCX $=$ double cortin

Gene expressed by migratory neuroblasts, this gene is mutated in the human X-linked lissencephaly and double cortex syndrome.

DLX-2 = distal-less homeobox 2

Transcription factor expressed by transit amplifying neural progenitors or type $\mathrm{C}$ cells, some Dlx-2 cells can differentiate into oligodendrocytes and astrocytes.

$\mathrm{EGF}=$ epidermal growth factor

Growth factor associated with proliferation or neural progenitors.

EMX2 = empty spiracles homeobox 2

This is expressed in the subventricular zone in vivo, associated with migration and proliferation of neural progenitors.

$\mathrm{EPO}=$ erythropoietin

Cytokine involved in erythropoiesis and is also a regulator of neural stem cell differentiation and proliferation.

FGF-2 = fibroblast growth factor

Growth factor that mediates self-renewal and proliferation of NSCs.
GDNF $=$ glial derived neurotrophic factor

Cytokine that mediates glial differentiation of NSCs.

GFAP $=$ glial fibrillary acidic protein

Intermediate filament protein expressed by bona fide neural stem cells and astrocytes.

GLI1 = glioma-associated oncogene 1

This is implicated in the transduction of the sonic hedgehog signal in neural stem cells.

Hes $1=$ homolog of the drosophila (hairy/enhancer of split 1)

Basic helix-loop-helix (bHLH) involved in self-renewal of and neurogenesis of NSCs.

Hes5 = homolog of drosophila (hairy/enhancer of split 5)

Basic helix-loop-helix (bHLH), which is associated with neurogenesis of NSCs.

Integrins

Cell adhesion molecules that are also bi-directional signaling molecules. Many integrins are associated with migration of neural stem cells (among them alpha 2, 3, 6, 7 and beta1 integrin.

Jagged 1

Ligand of the notch receptor that triggers a cascade of proteolytic cleavage that leads to the release of the intracellular part of the receptor from the membrane, allowing it to translocate to the nucleus and activate transcription factors important in neural stem cell differentiation.

LIF = leukemia inhibitor factor

Growth factor associated with self-renewal of neural stem cells.

LGL1 = lethal giant larvae-1

Putative tumor suppressor gene involved in asymmetric division of NSCs; mutation of this gene generates tumor-like growth for neural stem cells in drosophila and mice.

MMP2 = etalloproteinase-2

This is secreted by activated endothelial cells that can promote neural progenitor cell migration.

Musashi1

This molecule is a RNA-binding protein with prominent expression in precursor cells in the ventricular and subventricular zones and controls self-renewal capacity of NSCs. 
Neural progenitor cell 1

(Niemann-Pick disease, type C1)

Mutation in this gene has been shown to decrease self-renewal of NSCs.

Neurogenin 1

Basic helix-loop-helix (bHLH) transcription factor involved in determining neurogenesis.

\section{Neurogenin 2}

Basic helix-loop-helix (bHLH) transcription factor gene that plays an important role in neurogenesis from NSCs.

\section{Notch}

Notch proteins are single-pass transmembrane receptors that regulate cell fate decisions during development. These are involved in many stem cell systems. In the brain these are associated with NSC differentiation and gliogenesis.

Numb

Gene involved in neural progenitor asymmetric cell divisions and neurogenesis. Loss of Numb causes premature progenitor depletion and malformation of the neocortex and hippocampus.

Olig1 = oligodendrocyte lineage transcription factor-1

Helix-loop-helix (bHLH) transcription factors expressed in oligodendrocytes and oligodendrocyte precursors and is required for oligodendrocyte differentiation.

Olig2 = oligodendrocyte lineage transcription factor-2

Helix-loop-helix (bHLH) transcription factors expressed in oligodendrocytes and oligodendrocyte precursors and is required for oligodendrocyte differentiation.

p21 $=$ also known as cyclin-dependent kinase inhibitor $1 \mathrm{~A}$ or CDKN1A

Encodes a cyclin-dependent kinase inhibitor that induces cell-cycle arrest.

\section{p16INK4}

Cyclin-dependent kinase inhibitor-2A (CDKN2A) associated with cell-cycle inhibition and senescence and aging of neural stem cells.

p53 $=$ transformation-related protein 53

Tumor suppressor gene involved in a variety of human cancers and involves in self-renewal of NSCs.
PDGF $=$ platelet derived growth factor

Is implicated in the self-renewal and proliferation of B cells, as well as proliferation of oligodendrocyte progenitor cells.

PEDF $=$ pigment epithelium derived factor

Member of the serpin gene family (group of serine protease inhibitors); this molecule is associated with self-renewal of NSCs.

PSA-NCAM $=$ polysialylated neuronal cell adhesion molecule

This molecule is the polysialylated form of NCAM, which is important for migration of neuronal progenitors.

PTEN $=$ phosphatase and tensin homolog

Tumor suppressor gene associated with cell-cycle arrest is mutated in a variety of human cancers and is involved in self-renewal of NSCs.

Reelin

Gene expressed neural progenitors; mutation is this gene alters the migration, reelin is associated with reduce migration. Furthermore, blockade of reelin increases migration of neural progenitors.

SHH $=$ sonic hedgehog

Gene associated with brain morphogenesis and mediates proliferation and neurogenic and oligodendroglial differentiation of neural progenitors.

\section{SLIT2}

Mammalian homologous of the drosophila gene slit; it is a chemorepellent instead of chemoattractant of the subventricular zone and neural progenitor cells.

SOX2 $=$ sex determining region $\mathrm{y}$-box containing gene 2

Transcription factor associated with self-renewal of embryonic and neural stem cells.

SOX10 $=$ sex determining region y-related HMGbox gene 10

Encodes a transcription factor characterized by a DNA-binding motif known as the high mobility group (HMG) domain associated with oligodendrocyte maturation.

$\mathrm{TH}=$ tyrosine hormone

Steroid hormone required for terminal oligodendrocyte differentiation from NSCs and OPCs.

Wnt 3 = wingless-type mmtv integration site family, member 3

Member of the canonical wnt $\beta$ catenin signal pathways implicated in self-renewal and neurogenesis of neural progenitors. 
Wnt5 = wingless-type mmtv integration site family, member 5

Member of the canonical wnt $\beta$ catenin signal pathways implicated in self-renewal and neurogenesis of neural progenitors.

\section{REFERENCES}

1. Gage FH, Kempermann G, Palmer TD, Peterson DA, Ray J. Multipotent progenitor cells in the adult dentate gyrus. J Neurobiol 1998;36:249-266.

2. Alvarez-Buylla A, Temple S. Stem cells in the developing and adult nervous system. J Neurobiol 1998;36:105-110.

3. Sheen VL, Ganesh VS, Topcu M, et al. Mutations in ARFGEF2 implicate vesicle trafficking in neural progenitor proliferation and migration in the human cerebral cortex. Nat Genet 2004;36:6976.

4. Sheen VL, Ferland RJ, Harney M, et al. Impaired proliferation and migration in human Miller-Dieker neural precursors. Ann Neurol 2006;60:137-144.

5. Li J, Imitola J, Snyder EY, Sidman RL. Neural stem cells rescue nervous purkinje neurons by restoring molecular homeostasis of tissue plasminogen activator and downstream targets. J Neurosci 2006;26:7839-7848.

6. Fraidenraich D, Stillwell E, Romero E, et al. Rescue of cardiac defects in id knockout embryos by injection of embryonic stem cells. Science 2004;306:247-252.

7. Fraidenraich D, Benezra R. Embryonic stem cells prevent developmental cardiac defects in mice. Nat Clin Pract Cardiovasc Med 2006;3(Suppl 1):S14-17.

8. Pluchino S, Zanotti L, Rossi B, et al. Neurosphere-derived multipotent precursors promote neuroprotection by an immunomodulatory mechanism. Nature 2005;436:266-271.

9. Morshead CM, Benveniste P, Iscove NN, van der Kooy D. Hematopoietic competence is a rare property of neural stem cells that may depend on genetic and epigenetic alterations. Nat Med 2002;8:268-273.

10. Ziv Y, Ron N, Butovsky O, et al. Immune cells contribute to the maintenance of neurogenesis and spatial learning abilities in adulthood. Nat Neurosci 2006;9:268-275.

11. Magavi SS, Leavitt BR, Macklis JD. Induction of neurogenesis in the neocortex of adult mice [see comments]. Nature 2000;405: 951-955.

12. Flax JD, Aurora S, Yang C, et al. Engraftable human neural stem cells respond to developmental cues, replace neurons, and express foreign genes. Nat Biotechnol 1998;16:1033-1039.

13. Gokhan S, Song Q, Mehler MF. Generation and regulation of developing immortalized neural cell lines. Methods 1998;16:345358.

14. Johansson CB, Momma S, Clarke DL, Risling M, Lendahl U, Frisen J. Identification of a neural stem cell in the adult mammalian central nervous system. Cell 1999;96:25-34.

15. Mezey E, Chandross KJ, Harta G, Maki RA, McKercher SR. Turning blood into brain: cells bearing neuronal antigens generated in vivo from bone marrow [in process citation]. Science 2000;290:1779-1782.

16. Roy NS, Nakano T, Keyoung HM, et al. Telomerase immortalization of neuronally restricted progenitor cells derived from the human fetal spinal cord. Nat Biotechnol 2004;22:297-305.

17. Schuldiner M, Yanuka O, Itskovitz-Eldor J, Melton DA, Benvenisty N. From the cover: effects of eight growth factors on the differentiation of cells derived from human embryonic stem cells [in process citation]. Proc Natl Acad Sci U S A 2000;97:1130711312.

18. Tamaki S, Eckert K, He D, et al. Engraftment of sorted/expanded human central nervous system stem cells from fetal brain. J Neurosci Res 2002;69:976-986.

19. Gage FH. Mammalian neural stem cells. Science 2000;287:14331438.
20. Kondo T, Raff M. Oligodendrocyte precursor cells reprogrammed to become multipotential CNS stem cells [see comments]. Science 2000;289:1754-1757.

21. Marmur R, Mabie PC, Gokhan S, Song Q, Kessler JA, Mehler MF. Isolation and developmental characterization of cerebral cortical multipotent progenitors. Dev Biol 1998;204:577-591.

22. Ben-Hur T, Rogister B, Murray K, Rougon G, Dubois-Dalcq M. Growth and fate of PSA-NCAM+ precursors of the postnatal brain. J Neurosci 1998;18:5777-5788.

23. Palmer TD, Markakis EA, Willhoite AR, Safar F, Gage FH. Fibroblast growth factor-2 activates a latent neurogenic program in neural stem cells from diverse regions of the adult CNS J Neurosci 1999;19:8487-8497.

24. Laywell ED, Rakic P, Kukekov VG, Holland EC, Steindler DA. Identification of a multipotent astrocytic stem cell in the immature and adult mouse brain. Proc Natl Acad Sci U S A 2000;97: 13883-13888.

25. Lie DC, Dziewczapolski G, Willhoite AR, Kaspar BK, Shults $\mathrm{CW}$, Gage FH. The adult substantia nigra contains progenitor cells with neurogenic potential. J Neurosci 2002;22:6639-6649.

26. Villa A, Snyder EY, Vescovi A, Martinez-Serrano A. Establishment and properties of a growth factor-dependent, perpetual neural stem cell line from the human CNS. Exp Neurol 2000; 161:67-84.

27. Aboody KS, Brown A, Rainov NG, et al. From the cover: neural stem cells display extensive tropism for pathology in adult brain: evidence from intracranial gliomas [In Process Citation]. Proc Natl Acad Sci U S A 2000;97:12846-12851.

28. Chiasson BJ, Tropepe V, Morshead CM, van der Kooy D. Adult mammalian forebrain ependymal and subependymal cells demonstrate proliferative potential, but only subependymal cells have neural stem cell characteristics. J Neurosci 1999;19:4462-4471.

29. Clarke DL, Johansson CB, Wilbertz J, et al. Generalized potential of adult neural stem cells [see comments]. Science 2000;288: $1660-1663$.

30. Doetsch F, Caille I, Lim DA, Garcia-Verdugo JM, AlvarezBuylla A. Subventricular zone astrocytes are neural stem cells in the adult mammalian brain. Cell 1999;97:703-716.

31. McLaren FH, Svendsen CN, Van der Meide P, Joly E. Analysis of neural stem cells by flow cytometry: cellular differentiation modifies patterns of MHC expression [in process citation]. J Neuroimmunol 2001;112:35-46.

32. Morshead CM, Reynolds BA, Craig CG, et al. Neural stem cells in the adult mammalian forebrain: a relatively quiescent subpopulation of subependymal cells. Neuron 1994;13:1071-1082.

33. Gritti A, Bonfanti L, Doetsch F, et al. Multipotent neural stem cells reside into the rostral extension and olfactory bulb of adult rodents. J Neurosci 2002;22:437-445.

34. Quinones-Hinojosa A, Sanai N, Soriano-Navarro M, et al. Cellular composition and cytoarchitecture of the adult human subventricular zone: a niche of neural stem cells. J Comp Neurol 2006;494:415-434.

35. Sanai N, Tramontin AD, Quinones-Hinojosa A, et al. Unique astrocyte ribbon in adult human brain contains neural stem cells but lacks chain migration. Nature 2004;427:740-744.

36. Lois C, Alvarez-Buylla A. Proliferating subventricular zone cells in the adult mammalian forebrain can differentiate into neurons and glia. Proc Natl Acad Sci U S A 1993;90:2074-2077.

37. Doetsch F, Petreanu L, Caille I, Garcia-Verdugo JM, AlvarezBuylla A. EGF converts transit-amplifying neurogenic precursors in the adult brain into multipotent stem cells. Neuron 2002;36: 1021-1034.

38. Imura T, Kornblum HI, Sofroniew MV. The predominant neural stem cell isolated from postnatal and adult forebrain but not early embryonic forebrain expresses GFAP. J Neurosci 2003;23:28242832.

39. Arvidsson A, Collin T, Kirik D, Kokaia Z, Lindvall O. Neuronal replacement from endogenous precursors in the adult brain after stroke. Nat Med 2002;8:963-970.

40. Snyder EY, Vescovi AL. The possibilities/perplexities of stem cells [news]. Nat Biotechnol 2000;18:827-828.

41. Bjornson CR, Rietze RL, Reynolds BA, Magli MC, Vescovi AL. Turning brain into blood: a hematopoietic fate adopted by adult 
neural stem cells in vivo [see comments]. Science 1999;283:534-537.

42. Terada N, Hamazaki T, Oka M, et al. Bone marrow cells adopt the phenotype of other cells by spontaneous cell fusion. Nature 2002;416:542-545.

43. Ying QL, Nichols J, Evans EP, Smith AG. Changing potency by spontaneous fusion. Nature 2002;416:545-548.

44. Weimann JM, Charlton CA, Brazelton TR, Hackman RC, Blau HM. Contribution of transplanted bone marrow cells to Purkinje neurons in human adult brains. Proc Natl Acad Sci U S A 2003; 100:2088-2093.

45. Wagers AJ, Sherwood RI, Christensen JL, Weissman IL. Little evidence for developmental plasticity of adult hematopoietic stem cells. Science 2002;297:2256-2259.

46. Tourbah A, Linnington C, Bachelin C, Avellana-Adalid V, Wekerle $\mathrm{H}$, Baron-Van Evercooren A. Inflammation promotes survival and migration of the CG4 oligodendrocyte progenitors transplanted in the spinal cord of both inflammatory and demyelinated EAE rats. J Neurosci Res 1997;50:853-861.

47. Nait-Oumesmar B, Decker L, Lachapelle F, Avellana-Adalid V, Bachelin C, Van Evercooren AB. Progenitor cells of the adult mouse subventricular zone proliferate, migrate and differentiate into oligodendrocytes after demyelination. Eur J Neurosci 1999; 11:4357-4366.

48. Conover JC, Doetsch F, Garcia-Verdugo JM, Gale NW, Yancopoulos GD, Alvarez-Buylla A. Disruption of Eph/ephrin signaling affects migration and proliferation in the adult subventricular zone [in process citation]. Nat Neurosci 2000;3:1091-1097.

49. Forsberg-Nilsson K, Behar TN, Afrakhte M, Barker JL, McKay RD. Platelet-derived growth factor induces chemotaxis of neuroepithelial stem cells. J Neurosci Res 1998;53:521-530.

50. Imitola J, Raddassi K, Park KI, et al. Directed migration of neural stem cells to sites of CNS injury by the stromal cell-derived factor 1alpha/CXC chemokine receptor 4 pathway. Proc Natl Acad Sci U S A 2004;101:18117-18122.

51. Pluchino S, Quattrini A, Brambilla E, et al. Injection of adult neurospheres induces recovery in a chronic model of multiple sclerosis. Nature 2003;422:688-694.

52. Liu Y, Himes BT, Solowska J, et al. Intraspinal delivery of neurotrophin-3 using neural stem cells genetically modified by recombinant retrovirus. Exp Neurol 1999;158:9-26.

53. Palmer TD, Schwartz PH, Taupin P, Kaspar B, Stein SA, Gage FH. Cell culture. Progenitor cells from human brain after death. Nature 2001;411:42-43.

54. Nunes MC, Roy NS, Keyoung HM, et al. Identification and isolation of multipotential neural progenitor cells from the subcortical white matter of the adult human brain. Nat Med 2003;9: 439-447.

55. Windrem MS, Nunes MC, Rashbaum WK, et al. Fetal and adult human oligodendrocyte progenitor cell isolates myelinate the congenitally dysmyelinated brain. Nat Med 2004;10:93-97.

56. Wu P, Tarasenko YI, Gu Y, Huang LY, Coggeshall RE, Yu Y. Region-specific generation of cholinergic neurons from fetal human neural stem cells grafted in adult rat. Nat Neurosci 2002;5: $1271-1278$.

57. Fricker RA, Carpenter MK, Winkler C, Greco C, Gates MA, Bjorklund A. Site-specific migration and neuronal differentiation of human neural progenitor cells after transplantation in the adult rat brain. J Neurosci 1999;19:5990-6005.

58. Brustle O, Choudhary K, Karram K, et al. Chimeric brains generated by intraventricular transplantation of fetal human brain cells into embryonic rats. Nat Biotechnol 1998;16:1040-1044.

59. Bjorklund A, Lindvall O. Cell replacement therapies for central nervous system disorders. Nat Neurosci 2000;3:537-544.

60. Imitola J, Snyder EY, Khoury SJ. Genetic programs and responses of neural stem/progenitor cells during demyelination: potential insights into repair mechanisms in multiple sclerosis. Physiol Genomics 2003;14:171-197.

61. Snyder EY, Yoon C, Flax JD, Macklis JD. Multipotent neural precursors can differentiate toward replacement of neurons undergoing targeted apoptotic degeneration in adult mouse neocortex. Proc Natl Acad Sci U S A 1997;94:11663-11668.

62. Park KI, Liu S, Flax JD, Nissim S, Stieg PE, Snyder EY. Trans- plantation of neural progenitor and stem cells: developmental insights may suggest new therapies for spinal cord and other CNS dysfunction. J Neurotrauma 1999;16:675-687.

63. Riess P, Zhang C, Saatman KE, et al. Transplanted neural stem cells survive, differentiate, and improve neurological motor function after experimental traumatic brain injury. Neurosurgery 2002;51:1043-1052; discussion 1052-1044.

64. Park KI, Teng YD, Snyder EY. The injured brain interacts reciprocally with neural stem cells supported by scaffolds to reconstitute lost tissue. Nat Biotechnol 2002;20:1111-1117.

65. Ohab JJ, Fleming S, Blesch A, Carmichael ST. A neurovascular niche for neurogenesis after stroke. J Neurosci 2006;26:1300713016.

66. Auerbach JM, Eiden MV, McKay RD. Transplanted CNS stem cells form functional synapses in vivo. Eur J Neurosci 2000;12: $1696-1704$

67. Lundberg C, Englund U, Trono D, Bjorklund A, Wictorin K. Differentiation of the RN33B cell line into forebrain projection neurons after transplantation into the neonatal rat brain. Exp Neurol 2002;175:370-387.

68. Vroemen M, Aigner L, Winkler J, Weidner N. Adult neural progenitor cell grafts survive after acute spinal cord injury and integrate along axonal pathways. Eur J Neurosci 2003;18: $743-751$.

69. Yamamoto S, Nagao M, Sugimori M, et al. Transcription factor expression and Notch-dependent regulation of neural progenitors in the adult rat spinal cord. J Neurosci 2001;21:9814-9823.

70. Ourednik J, Ourednik V, Lynch WP, Schachner M, Snyder EY. Neural stem cells display an inherent mechanism for rescuing dysfunctional neurons. Nat Biotechnol 2002;20:1103-1110.

71. Hagan M, Wennersten A, Meijer X, Holmin S, Wahlberg L, Mathiesen T. Neuroprotection by human neural progenitor cells after experimental contusion in rats. Neurosci Lett 2003;351: $149-152$.

72. Haughey NJ, Nath A, Chan SL, Borchard AC, Rao MS, Mattson MP. Disruption of neurogenesis by amyloid beta-peptide, and perturbed neural progenitor cell homeostasis, in models of Alzheimer's disease. J Neurochem 2002;83:1509-1524.

73. Mehta V, Hong M, Spears J, Mendez I. Enhancement of graft survival and sensorimotor behavioral recovery in rats undergoing transplantation with dopaminergic cells exposed to glial cell linederived neurotrophic factor. J Neurosurg 1998;88:1088-1095.

74. Lindvall O. Neural transplantation in Parkinson's disease. Novartis Found Symp 2000;231:110-123; discussion 123-118, 145117.

75. Piccini P, Lindvall O, Bjorklund A, et al. Delayed recovery of movement-related cortical function in Parkinson's disease after striatal dopaminergic grafts. Ann Neurol 2000;48:689-695.

76. Anton R, Kordower JH, Maidment NT, et al. Neural-targeted gene therapy for rodent and primate hemiparkinsonism. Exp Neurol 1994;127:207-218.

77. Lundberg C, Field PM, Ajayi YO, Raisman G, Bjorklund A. Conditionally immortalized neural progenitor cell lines integrate and differentiate after grafting to the adult rat striatum. A combined autoradiographic and electron microscopic study. Brain Res 1996; 737:295-300.

78. Svendsen CN, Caldwell MA, Shen J, et al. Long-term survival of human central nervous system progenitor cells transplanted into a rat model of Parkinson's disease. Exp Neurol 1997;148:135-146.

79. Bjugstad KB, Redmond DE, Jr., Teng YD, et al. Neural stem cells implanted into MPTP-treated monkeys increase the size of endogenous tyrosine hydroxylase-positive cells found in the striatum: a return to control measures. Cell Transplant 2005;14:183192.

80. Redmond DE, Jr., Bjugstad KB, Teng YD, et al. From the cover: behavioral improvement in a primate Parkinson's model is associated with multiple homeostatic effects of human neural stem cells. Proc Natl Acad Sci U S A 2007;104:12175-12180.

81. Kim JH, Auerbach JM, Rodriguez-Gomez JA, et al. Dopamine neurons derived from embryonic stem cells function in an animal model of Parkinson's disease. Nature 2002;418:50-56.

82. Kim DW, Chung S, Hwang M, et al. Stromal cell-derived inducing activity, Nurr1, and signaling molecules synergistically in- 
duce dopaminergic neurons from mouse embryonic stem cells. Stem Cells 2006;24:557-567.

83. Roy NS, Cleren C, Singh SK, Yang L, Beal MF, Goldman SA. Functional engraftment of human ES cell-derived dopaminergic neurons enriched by coculture with telomerase-immortalized midbrain astrocytes. Nat Med 2006;12:1259-1268.

84. Kornek B, Storch MK, Weissert R, et al. Multiple sclerosis and chronic autoimmune encephalomyelitis: a comparative quantitative study of axonal injury in active, inactive, and remyelinated lesions. Am J Pathol 2000;157:267-276.

85. Imitola $J$, Chitnis $T$, Khoury SJ. Insights into the molecular pathogenesis of progression in multiple sclerosis: potential implications for future therapies. Arch Neurol 2006;63:25-33.

86. Einstein O, Fainstein N, Vaknin I, et al. Neural precursors attenuate autoimmune encephalomyelitis by peripheral immunosuppression. Ann Neurol 2007;61:209-218.

87. Yandava BD, Billinghurst LL, Snyder EY. "Global" cell replacement is feasible via neural stem cell transplantation: evidence from the dysmyelinated shiverer mouse brain. Proc Natl Acad Sci U S A 1999;96:7029-7034.

88. Hammang JP, Archer DR, Duncan ID. Myelination following transplantation of EGF-responsive neural stem cells into a myelin-deficient environment. Exp Neurol 1997;147:84-95.

89. Milward EA, Lundberg CG, Ge B, Lipsitz D, Zhao M, Duncan ID. Isolation and transplantation of multipotential populations of epidermal growth factor-responsive, neural progenitor cells from the canine brain. J Neurosci Res 1997;50:862-871.

90. Liu S, Qu Y, Stewart TJ, et al. Embryonic stem cells differentiate into oligodendrocytes and myelinate in culture and after spinal cord transplantation. Proc Natl Acad Sci U S A 2000;97:61266131.

91. Brustle O, Jones KN, Learish RD, et al. Embryonic stem cellderived glial precursors: a source of myelinating transplants [see comments]. Science 1999;285:754-756.

92. Archer DR, Cuddon PA, Lipsitz D, Duncan LD. Myelination of the canine central nervous system by glial cell transplantation: a model for repair of human myelin disease. Nat Med 1997;3:5459.

93. Espinosa de los Monteros A, Zhao P, Huang C, et al. Transplantation of CG4 oligodendrocyte progenitor cells in the myelindeficient rat brain results in myelination of axons and enhanced oligodendroglial markers. J Neurosci Res 1997;50:872-887.

94. Zhang SC, Ge B, Duncan ID. Adult brain retains the potential to generate oligodendroglial progenitors with extensive myelination capacity. Proc Natl Acad Sci U S A 1999;96:4089-4094.

95. Imaizumi T, Lankford KL, Burton WV, Fodor WL, Kocsis JD. Xenotransplantation of transgenic pig olfactory ensheathing cells promotes axonal regeneration in rat spinal cord. Nat Biotechnol 2000;18:949-953.

96. Kato T, Honmou O, Uede T, Hashi K, Kocsis JD. Transplantation of human olfactory ensheathing cells elicits remyelination of demyelinated rat spinal cord. Glia 2000;30:209-218.

97. Barnett SC, Alexander CL, Iwashita Y, et al. Identification of a human olfactory ensheathing cell that can effect transplant-mediated remyelination of demyelinated CNS axons. Brain 2000; 123 (Pt 8):1581-1588.

98. Kohama I, Lankford KL, Preiningerova J, White FA, Vollmer TL, Kocsis JD. Transplantation of cryopreserved adult human Schwann cells enhances axonal conduction in demyelinated spinal cord. J Neurosci 2001;21:944-950.

99. Franklin RJ, Blakemore WF. Transplanting oligodendrocyte progenitors into the adult CNS. J Anat 1997;190:23-33.

100. Rosario CM, Yandava BD, Kosaras B, Zurakowski D, Sidman RL, Snyder EY. Differentiation of engrafted multipotent neural progenitors towards replacement of missing granule neurons in meander tail cerebellum may help determine the locus of mutant gene action. Development 1997;124:4213-4224.

101. Snyder EY, Taylor RM, Wolfe JH. Neural progenitor cell engraftment corrects lysosomal storage throughout the MPS VII mouse brain. Nature 1995;374:367-370.

102. Meng XL, Shen JS, Ohashi T, Maeda H, Kim SU, Eto Y. Brain transplantation of genetically engineered human neural stem cells globally corrects brain lesions in the mucopolysaccharidosis type VII mouse. J Neurosci Res 2003;74:266-277.

103. Lacorazza HD, Flax JD, Snyder EY, Jendoubi M. Expression of human beta-hexosaminidase alpha-subunit gene (the gene defect of Tay-Sachs disease) in mouse brains upon engraftment of transduced progenitor cells. Nat Med 1996;2:424-429.

104. Torchiana E, Lulli L, Cattaneo E, et al. Retroviral-mediated transfer of the galactocerebrosidase gene in neural progenitor cells. Neuroreport 1998;9:3823-3827.

105. Lee JP, Jeyakumar M, Gonzalez R, et al. Stem cells act through multiple mechanisms to benefit mice with neurodegenerative metabolic disease. Nat Med 2007;13:439-447.

106. Ehtesham M, Kabos P, Gutierrez MA, et al. Induction of glioblastoma apoptosis using neural stem cell-mediated delivery of tumor necrosis factor-related apoptosis-inducing ligand. Cancer Res 2002;62:7170-7174.

107. Ehtesham M, Kabos P, Kabosova A, Neuman T, Black KL, Yu JS. The use of interleukin 12-secreting neural stem cells for the treatment of intracranial glioma. Cancer Res 2002;62:5657-5663.

108. Benedetti S, Pirola B, Pollo B, et al. Gene therapy of experimental brain tumors using neural progenitor cells. Nat Med 2000;6:447450 .

109. Jackson EL, Garcia-Verdugo JM, Gil-Perotin S, et al. PDGFR alpha-positive B cells are neural stem cells in the adult SVZ that form glioma-like growths in response to increased PDGF signaling. Neuron 2006;51:187-199.

110. Quinones-Hinojosa A, Chaichana K. The human subventricular zone: a source of new cells and a potential source of brain tumors. Exp Neurol 2007;205:313-324.

111. Monje ML, Mizumatsu S, Fike JR, Palmer TD. Irradiation induces neural precursor-cell dysfunction. Nat Med 2002;8:955962.

112. Monje ML, Toda H, Palmer TD. Inflammatory blockade restores adult hippocampal neurogenesis. Science 2003;302:1760-1765.

113. Imitola J, Comabella $\mathrm{M}$, Chandraker $\mathrm{AK}$, et al. Neural stem/ progenitor cells express costimulatory molecules that are differentially regulated by inflammatory and apoptotic stimuli. Am J Pathol 2004;164:1615-1625.

114. Gensert JM, Goldman JE. Endogenous progenitors remyelinate demyelinated axons in the adult CNS. Neuron 1997;19:197-203.

115. Wolswijk G. Chronic stage multiple sclerosis lesions contain a relatively quiescent population of oligodendrocyte precursor cells. J Neurosci 1998;18:601-609.

116. Rogister B, Ben-Hur T, Dubois-Dalcq M. From neural stem cells to myelinating oligodendrocytes. Mol Cell Neurosci 1999;14: 287-300.

117. Lu P, Jones LL, Snyder EY, Tuszynski MH. Neural stem cells constitutively secrete neurotrophic factors and promote extensive host axonal growth after spinal cord injury. Exp Neurol 2003; 181:115-129.

118. Ourednik V, Ourednik J, Flax JD, et al. Segregation of human neural stem cells in the developing primate forebrain. Science 2001;293:1820-1824.

119. Snyder EY, Deitcher DL, Walsh C, Arnold-Aldea S, Hartwieg EA, Cepko CL. Multipotent neural cell lines can engraft and participate in development of mouse cerebellum. Cell 1992;68: $33-51$.

120. Tang Y, Shah K, Messerli SM, Snyder E, Breakefield X, Weissleder R. In vivo tracking of neural progenitor cell migration to glioblastomas. Hum Gene Ther 2003;14:1247-1254.

121. Yang M, Stull ND, Berk MA, Snyder EY, Iacovitti L. Neural stem cells spontaneously express dopaminergic traits after transplantation into the intact or 6-hydroxydopamine-lesioned rat. Exp Neurol 2002;177:50-60.

122. Rothstein JD, Snyder EY. Reality and immortality-neural stem cells for therapies. Nat Biotechnol 2004;22:283-285.

123. De Filippis L, Lamorte G, Snyder EY, Malgaroli A, Vescovi AL. A novel, immortal and multipotent human neural stem cell line generating functional neurons and oligodendrocytes. Stem Cells 2007 Jun 7; [Epub ahead of print].

124. Reynolds BA, Rietze RL. Neural stem cells and neurospheresre-evaluating the relationship. Nat Methods 2005;2:333-336. 
125. Singec I, Knoth R, Meyer RP, et al. Defining the actual sensitivity and specificity of the neurosphere assay in stem cell biology. Nat Methods 2006;3:801-806.

126. Fults D, Pedone C, Dai C, Holland EC. MYC expression promotes the proliferation of neural progenitor cells in culture and in vivo. Neoplasia 2002;4:32-39.

127. Sanai N, Alvarez-Buylla A, Berger MS. Neural stem cells and the origin of gliomas. N Engl J Med 2005;353:811-822.

128. Foroni C, Galli R, Cipelletti B, et al. Resilience to transformation and inherent genetic and functional stability of adult neural stem cells ex vivo. Cancer Res 2007;67:3725-3733.

129. Uhrbom L, Dai C, Celestino JC, Rosenblum MK, Fuller GN, Holland EC. Ink4a-Arf loss cooperates with KRas activation in astrocytes and neural progenitors to generate glioblastomas of various morphologies depending on activated Akt. Cancer Res 2002;62:5551-5558.

130. Gabay L, Lowell S, Rubin LL, Anderson DJ. Deregulation of dorsoventral patterning by FGF confers trilineage differentiation capacity on CNS stem cells in vitro. Neuron 2003;40:485-499.

131. Thored P, Arvidsson A, Cacci E, et al. Persistent production of neurons from adult brain stem cells during recovery after stroke. Stem Cells 2006;24:739-747.

132. Picard-Riera N, Decker L, Delarasse C, et al. Experimental autoimmune encephalomyelitis mobilizes neural progenitors from the subventricular zone to undergo oligodendrogenesis in adult mice. Proc Natl Acad Sci U S A 2002;99:13211-13216.

133. Zappia E, Casazza S, Pedemonte E, et al. Mesenchymal stem cells ameliorate experimental autoimmune encephalomyelitis inducing T-cell anergy. Blood 2005;106:1755-1761.
134. Muraoka K, Shingo T, Yasuhara T, et al. The high integration and differentiation potential of autologous neural stem cell transplantation compared with allogeneic transplantation in adult rat hippocampus. Exp Neurol 2006;199:311-327.

135. Song $\mathrm{H}$, Stevens CF, Gage FH. Astroglia induce neurogenesis from adult neural stem cells. Nature 2002;417:39-44.

136. Faijerson J, Tinsley RB, Aprico K, et al. Reactive astrogliosis induces astrocytic differentiation of adult neural stem/progenitor cells in vitro. J Neurosci Res 2006;84:1415-1424.

137. Aarum J, Sandberg K, Haeberlein SL, Persson MA. Migration and differentiation of neural precursor cells can be directed by microglia. Proc Natl Acad Sci U S A 2003;100:15983-15988.

138. Zhang SC, Goetz BD, Duncan ID. Suppression of activated microglia promotes survival and function of transplanted oligodendroglial progenitors. Glia 2003;41:191-198.

139. Butovsky O, Landa G, Kunis G, et al. Induction and blockage of oligodendrogenesis by differently activated microglia in an animal model of multiple sclerosis. J Clin Invest 2006;116:905-915.

140. Miller JT, Bartley JH, Wimborne HJ, et al. The neuroblast and angioblast chemotaxic factor SDF-1 (CXCL12) expression is briefly up regulated by reactive astrocytes in brain following neonatal hypoxic-ischemic injury. BMC Neurosci 2005;6:63.

141. Corti S, Locatelli F, Papadimitriou D, et al. Multipotentiality, homing properties, and pyramidal neurogenesis of CNS-derived LeX(ssea-1)+/CXCR4+ stem cells. Faseb J 2005;19:1860-1862.

142. Robin AM, Zhang ZG, Wang L, et al. Stromal cell-derived factor 1alpha mediates neural progenitor cell motility after focal cerebral ischemia. J Cereb Blood Flow Metab 2006;26:125-134. 